COMUNICAÇÃO CIENTÍFICA

\title{
OCORRÊNCIA DE DECLIINIO DOS CITROS NA REGIÃO NOROESTE DO PARANÁ ${ }^{1}$
}

\author{
PEDRO ANTONIO MARTINS AULER ${ }^{2}$, MARCOS ANTONIO PAVAN ${ }^{3}$, \\ CARMEN SILVIA VIERA JANEIRO NEVES ${ }^{4}$, EDUARDO FERMINO CARLOS ${ }^{5}$
}

RESUMO - O declínio dos citros é uma anomalia vascular que provoca grandes prejuízos à produção de citros. Sua causa é controversa, e fatores bióticos e abióticos têm sido sugeridos. Embora detectado desde 1979 afetando plantas em pomares do Estado de São Paulo, sua ocorrência ainda não foi relatada em certas regiões produtoras de citros do Brasil. Este trabalho teve como objetivo comprovar, por meio de testes diagnósticos, a ocorrência do declínio dos citros no polo citrícola da região noroeste do Paraná. Foi realizado em pomar experimental de laranjeira 'Valência' (Citrus sinensis L. Osb.) enxertada em limoeiro 'Cravo' (C. limonia Osb.) plantado em 1994 no município de Nova Esperança. Os testes de teor de zinco na madeira e da absorção de água com injeção no tronco confirmaram a presença de declínio dos citros. Os sintomas da doença foram caracterizados por folhas pequenas, sem brilho e com menor turgidez, redução nos fluxos de brotação, morte da extremidade de ramos e redução da produção e do tamanho de frutos. A primeira ocorrência de declínio dos citros foi observada aos sete anos após o plantio, e aos quinze anos atingiu $31 \%$ das plantas. Termos para indexação: Citrus sinensis, perda de produtividade, testes de indexação, sintomas.

\section{OCCURRENCE OF CITRUS BLIGHT IN THE NORTHWESTERN AREA OF THE STATE OF PARANA, BRAZIL}

\begin{abstract}
Citrus blight is a vascular abnormality that affects tree production. It is still under debate if it has biotic or abiotic causes. Although it has been detected since 1979 affecting plants in orchards of the State of Sao Paulo, its occurrence was not confirmed in certain citrus producing areas of Brazil. The objective of the present study was to confirm by diagnostic tests the occurrence of citrus blight in the citrus area in the northwestern region of the state of Parana. The study was done at one experimental orchard with 'Valencia' sweet orange (Citrus sinensis L. Osb.) grafted on 'Rangpur' lime (C. limonia Osb.), planted in 1994 and located at Nova Esperança county. The diagnostic tests of zinc content in the trunk of the plant and the injection of water confirmed the presence of citrus blight. The symptoms of plant decline were characterized by small, opaque and less turgid leaves, reduction of new sprout flushes, twig dieback, reduction of crop and production of smaller fruits. The first occurrence of citrus blight was observed seven years after the planting time and at fifteen years it reached $31 \%$ of all plants.
\end{abstract}

Index terms: Citrus sinensis, productivity loss, indexing tests, symptoms.

\footnotetext{
${ }_{1}^{1}$ (Trabalho 081-10). Recebido em: 24-03-2010. Aceito para publicação em: 19-11-2010.Desenvolvido com apoio da Fundação Araucária e CNPq.

${ }^{2}$ Eng $^{\circ}$. Agr ${ }^{\circ}$., Dr., Pesquisador da Área de Fitotecnia, Instituto Agronômico do Paraná - IAPAR, 87701-970, C. P. 564, Paranavaí-PR, Brasil. E-mail: aulerpe@iapar.br

${ }^{3}$ Eng $^{\circ}$. Agr ${ }^{\circ}$, Ph.D., Pesquisador da Área de Solos, IAPAR, Londrina-PR. E-mail: mpavan@iapar.br

${ }^{4} \mathrm{Eng}^{\mathrm{a}}$. Agr ${ }^{\mathrm{a}}$, Dr ${ }^{\mathrm{a}}$, Professora do Departamento de Agronomia, Universidade Estadual de Londrina. E-mail: csvjneve@uel.br

${ }^{5} \mathrm{Eng}^{\circ}$. Agr ${ }^{\circ}$, Ph.D., Pesquisador da Área de Melhoramento Genético, IAPAR, Londrina-PR. E-mail: efcarlos@iapar.br
} 
O declínio dos citros é uma anomalia de natureza vascular que compromete a translocação de seiva bruta nas plantas. Foi relatado pela primeira vez na Flórida (EUA) por Underwood, em 1891, citado por Swingle e Webber (1896), e é encontrado nas principais zonas citrícolas do mundo, com exceção dos países do Mediterrâneo e dos estados americanos da Califórnia e do Arizona (LARANJEIRA et al., 2005). No Brasil, sua ocorrência foi relatada pela primeira vez no Estado de São Paulo por Rodrigues et al. (1979) e, posteriormente, em Sergipe, Bahia e Minas Gerais (BERETTA; ROSSETTI, 1990). No polo citrícola instalado a partir do final da década de 1980, nas regiões norte e noroeste do Paraná, ainda não há relatos na literatura comprovando a ocorrência de declínio, embora observações a campo de plantas com sintomas visuais característicos desta doença sugerem que a mesma já vem ocorrendo pelo menos há uma década.

Os sintomas geralmente se manifestam em plantas com quatro ou mais anos de idade e caracterizam-se inicialmente pela perda de brilho das folhas e ausência de brotações novas com drástica redução da produção a partir do segundo ano após o início dos sintomas, quando toda a planta passa a definhar (TIMMER, 1990; BERETTA; ROSSETTI, 1990). No Estado de São Paulo, estima-se que entre 6 e 8\% das plantas são afetadas anualmente pelo declínio e tornam-se improdutivas (BALDASSARI et al., 2003), reduzindo a produtividade e a vida útil dos pomares, e onerando os custos de produção.

As plantas com declínio apresentam uma disfunção do xilema caracterizada pela restrição no transporte de água por obstruções amorfas e filamentosas, e pela acumulação de zinco no xilema secundário do tronco e nos tecidos do floema (ALBRIGO; YOUNG, 1981; WUTSCHER, 1981; BERETTA et al., 1988). Esses sintomas são específicos desta anomalia e podem ser usados para diferenciá-la de outros problemas que também causam definhamento de plantas cítricas, como huanglongbing (HLB), declínio por nematoides, tristeza, gomose de Phytophthora, exocorte, xiloporose e morte súbita dos citros (WUTSCHER et al., 1977; WUTSCHER, 1981; LEE et al., 1984). A técnica da injeção de água com seringa no tronco (LEE et al., 1984), em combinação com o exame visual dos sintomas, é altamente confiável para o diagnóstico do declínio dos citros, podendo ainda ser usado, adicionalmente, o teste do conteúdo de zinco na casca ou na madeira do tronco (WUTSCHER et al., 1977; LEE et al., 1984), além de testes serológicos (DERRICK et al., 1992) e da microscopia eletrônica para observação de obstruções amorfas nos vasos do xilema (BERETTA et al., 1988).

Muitos estudos têm sido conduzidos para determinar as causas do declínio, mas ainda há controvérsias quanto a sua origem ser biótica ou abiótica (BOMAN et al., 2005). As repetidas demonstrações de que todos os sintomas associados ao declínio podem ser reproduzidos por enxertia de raízes (TUCKER et al., 1984; ROSSETTI et al., 1991) e a distribuição das plantas afetadas nos pomares de forma agregada são as principais evidências de que um agente infeccioso possa estar envolvido (DERRICK, 1998; CARLOS et al., 2000). Por outro lado, o insucesso nas tentativas de transmitir o declínio por enxertia de gemas de plantas sintomáticas em plantas sadias (LIMA; BORDUCCHI, 1982; ALBRIGO et al., 1992), assim como o não isolamento de um patógeno após décadas de pesquisa corroboram a hipótese de uma provável causa não infecciosa (CASTRO, 1991; BERGER, 1998).

O controle do declínio tem sido realizado, principalmente, com o uso de porta-enxertos tolerantes, como as tangerineiras 'Cleópatra' (Citrus reshni hort. ex Tan.) e 'Sunki' (Citrus sunki hort. ex Tan.) e o citrumeleiro 'Swingle' (Citrus paradise Mac. x Poncirus trifoliata L. Raf.), enquanto o limoeiro 'Cravo' é considerado um dos porta-enxertos mais suscetíveis (POMPEU JUNIOR, 2005).

Este trabalho teve como objetivo comprovar, por meio de testes diagnósticos, a ocorrência do declínio dos citros no polo citrícola da região noroeste do Estado do Paraná. Foi realizado em área experimental implantada em janeiro de 1994, em Latossolo Vermelho distrófico, textura arenosa/ média, localizado a $23^{\circ} 09^{\prime} 12^{\prime \prime} \mathrm{S}$ e $52^{\circ} 08^{\prime} 40^{\prime \prime} \mathrm{O}$ no município de Nova Esperança. O clima é caracterizado como subtropical Cfa (classificação de Köppen) com concentração das chuvas no verão e período mais seco no inverno, temperatura média anual de $22^{\circ} \mathrm{C}$ e precipitação anual de $1.400 \mathrm{~mm}$.

As avaliações da incidência de declínio foram realizadas anualmente, no período de setembro a novembro, desde o início da implantação do experimento, em 1994, em 36 plantas de laranjeira 'Valência' (Citrus sinensis L. Osb.), enxertadas sobre limoeiro 'Cravo' (Citrus limonia Osb.), registrandose, planta por planta, a data do início da manifestação dos sintomas visuais, caracterizados, inicialmente, pela presença de folhas sem brilho e ausência de brotações novas.

O diagnóstico do declínio foi confirmado por meio de testes de indexação de teores de zinco no tecido do tronco (WUTSCHER et al., 1977), realizado em outubro de 2008, e da absorção de água no tronco injetada por seringa (LEE et al., 1984), 
realizado em dezembro de 2008. Ambos os testes foram aplicados em todas as plantas com sintomas de declínio, e para cada uma delas foram realizados testes em, pelo menos, uma planta assintomática, com aparência sadia. Para o teste do teor de zinco foram coletados aproximadamente $2 \mathrm{~g}$ de tecido do tronco, que foi seco em estufa com circulação de ar a $60^{\circ} \mathrm{C}$, por 60 horas. A extração do zinco foi realizada por digestão úmida nitroperclórica, e a determinação da sua concentração, em espectrofotometria de emissão atômica com indução de plasma (MYAZAWA et al., 1999). O teste de injeção de água, inicialmente, foi realizado com auxílio de furadeira portátil, por meio de um furo no tronco, com $3 \mathrm{~cm}$ de profundidade e diâmetro de $3,2 \mathrm{~mm}$, localizado a $25 \mathrm{~cm}$ acima da linha de enxertia; o teste consistiu em introduzir a ponta (sem agulha) de uma seringa plástica contendo $10 \mathrm{ml}$ de água neste orifício e empurrar o seu êmbolo com a mão de um operador, por um período de tempo máximo de $30 \mathrm{~s}$. Os resultados dos teores de zinco no tronco e a absorção de água pelo teste da seringa foram submetidos ao teste $\mathrm{t}(\mathrm{P} \leq 0,05)$, comparando-se os resultados obtidos de plantas assintomáticas com os de plantas com sintomas de declínio.

Os principais sintomas observados nas plantas avaliadas com declínio corresponderam aos observados em São Paulo (BERETTA; ROSSETTI, 1990) e na Flórida (TIMMER, 1990), caracterizados por folhas pequenas, sem brilho e com menor turgidez, redução e alteração nos fluxos de brotação, florescimento extemporâneo, morte da extremidade de ramos, redução da produção e do tamanho de frutos.

A maior concentração de zinco e a reduzida absorção de água em troncos de laranjeiras 'Valência', enxertadas em limoeiro 'Cravo' com os sintomas visuais descritos acima, comprovam a ocorrência do declínio das plantas cítricas (Tabela 1). As plantas com declínio tiveram uma redução de 26 vezes na absorção de água e um aumento de 2,5 vezes nos teores de zinco no tronco em relação às plantas assintomáticas.

Estes resultados estão de acordo Lee et al. (1984), que relataram que plantas com aparência sadia absorveram, em média, mais do que $1 \mathrm{ml}$ de água em 1 segundo, em todas as plantas avaliadas na Flórida (EUA) e na África do Sul, enquanto plantas com sintomas severos do declínio/blight usualmente não absorveram água ou ocasionalmente 1-2 ml em 30 segundos. Concordam também com os resultados obtidos por Wutscher (1981), que verificaram que os valores de zinco no xilema do tronco foram usualmente 2 a 3 vezes mais altos em plantas com declínio/blight de laranjeira 'Valência' sobre limoeiro 'Rugoso'. Wutscher et al. (1977) também encontraram valores de zinco que variaram de 13 a 26 ppm para plantas com declínio e de 2 a 6 ppm para plantas sadias de laranjeira 'Valência' sobre limoeiro 'Rugoso'.

A ocorrência de declínio teve início em 2001, sete anos após o plantio, quando atingiu 5,6 \% das plantas. Em 2008, 15 anos após o plantio, a incidência atingiu 30,5\% das plantas (Figura 1). Esses resultados indicam índices ainda mais elevados que os obtidos por Lima e Borducchi (1982), que observaram que a incidência de declínio atingiu $24 \%$ das plantas de laranjeira 'Valência' sobre 'Cravo' com 22 anos de idade, em pomar comercial irrigado, localizado em Mogi-Guaçu, São Paulo.

A taxa de incidência de declínio nos últimos dois anos avaliados (2007 e 2008) foi de 5,6\%, equivalente à observada em 2001, ano em que a primeira ocorrência foi registrada (Figura 1). Considerando o período de 8 anos, de 2001 a 2008, a taxa média de incidência foi de 3,8 \% ao ano. No Estado de São Paulo, são estimadas taxas anuais de incidência de declínio nos pomares de 6 a $8 \%$ (BALDASSARI et al., 2003), na África do Sul de 2,5 a 3,5\% ao ano (MARAIS, 1988) e na Flórida (EUA) podem chegar até $8 \%$, dependendo do porta-enxerto utilizado (YOUNG et al., 1982).

No presente trabalho, as plantas com declínio tornaram-se improdutivas a partir do segundo ano após o início dos sintomas, que se agravaram com o passar dos anos, porém, sem provocar a morte de nenhuma planta, como também constatado por Marais (1988), enquanto Beretta e Rossetti (1990) observaram que, dependendo da região, as plantas podem morrer.

Os resultados obtidos comprovam que o declínio dos citros foi a causa do depauperamento de plantas na área experimental e que o polo citrícola estabelecido há pouco mais de 20 anos na região noroeste do Paraná vem sendo afetado economicamente por este problema, pois têm sido observadas plantas improdutivas em seus pomares, com sintomas semelhantes aos aqui caracterizados. Confirmou-se, também, que o limoeiro 'Cravo' apresenta suscetibilidade a esta anomalia. 
TABELA 1 - Absorção de água e teores de zinco no tronco de laranjeiras 'Valência' enxertadas em limoeiro 'Cravo', Nova Esperança-PR.

\begin{tabular}{lcc}
\hline Condição da planta & \multicolumn{2}{c}{ Testes de indexação } \\
& $\begin{array}{c}\text { Absorção de água } \\
\left(\mathrm{ml} \mathrm{s}^{-1}\right)\end{array}$ & $\begin{array}{c}\text { Zinco } \\
\left(\mathrm{mg} \mathrm{kg}^{-1}\right)\end{array}$ \\
\hline Com declínio & $0,04 \mathrm{~b}^{\mathrm{z}}$ & $12,02 \mathrm{a}$ \\
Assintomática & $1,04 \mathrm{a}$ & $4,83 \mathrm{~b}$ \\
\hline
\end{tabular}

${ }^{\mathrm{Y}} \mathrm{Em}$ ambos os testes, foram utilizadas 9 plantas com declínio dos citros e 11 plantas assintomáticas $(\mathrm{N}=20) ;{ }^{\mathrm{z}}$ Médias seguidas por letras diferentes na coluna diferem entre si, pelo teste $\mathrm{t}(\mathrm{P} \leq 0,05)$.

Incidência anual $\mathbf{\square}$ Incidência acumulada

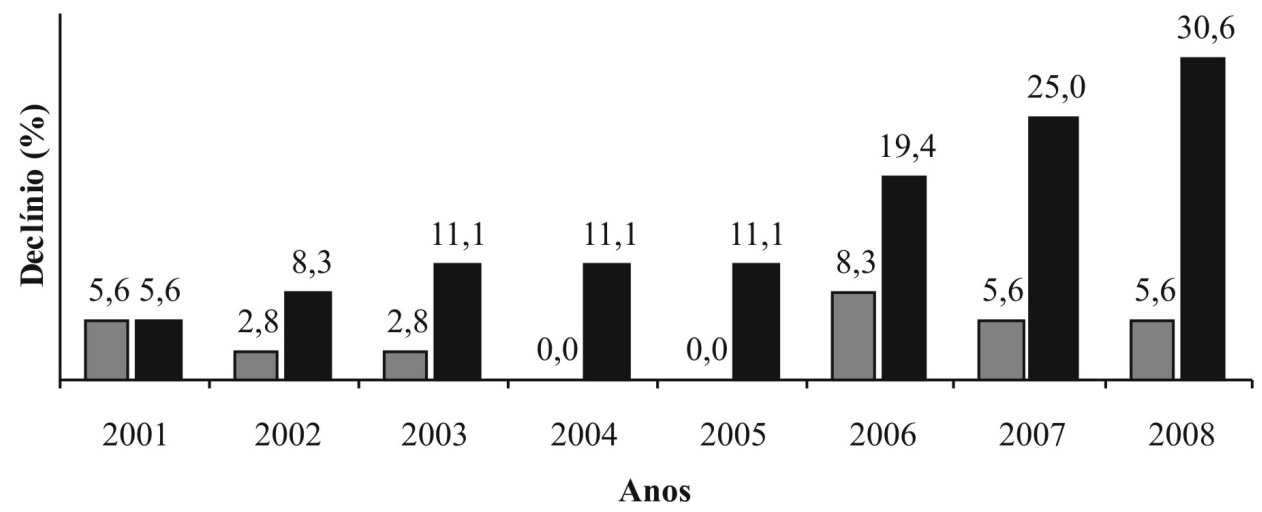

FIGURA 1 - Incidência anual e acumulada de declínio dos citros em plantas de laranjeira 'Valência' enxertada em limoeiro 'Cravo', plantio em 1994, Nova Esperança- PR, ( $N=36$ ).

\section{AGRADECIMENTOS}

Aos citricultores Gilberto e Antônio Pratinha, pelo apoio na condução do experimento, e aos técnicos Paulo Manuel de Lima e Wilson Schvieczrski, pelo auxílio nas avaliações realizadas.

\section{REFERÊNCIAS}

ALBRIGO, L.G.; TIMMER, L.W.; DERRICK, K.S.; TUCKER, D.P.H.; GRAHAM, J.H. Failure to transmit citrus blight by limb grafts. In: CONFERENCE OF THE IOCV, 12., 1992. New Delhi. Proceedings... University of Califórnia, 1992. p. 127-130.

ALBRIGO, L.G.; YOUNG, R.H. Phloem zinc accumulation in citrus trees affected with blight. Hortscience, Alexandria, v.16, p.158-160, 1981.

BALDASSARI, R.B.; GÓES, A.; TANNURI, F. Declínio dos citros: Algo a ver com o sistema de produção de mudas cítricas? Revista Brasileira de Fruticultura, Jaboticabal, v.25, p.357-360, 2003.
BERETTA, M.J.G.; ROSSETTI, V. Declínio dos citros - Uma doença transmissível. In: SEMINÁRIO INTERNACIONAL SOBRE PORTA-ENXERTOS DE CITROS, 1., 1990, Bebedouro. Anais... p.211221.

BERETTA, M.J.G.; ROSSETTI, V.; BRLANSKY, R.H.; LEE, R.F. A comparison of histochemical staining reactions of the xylem occlusions in trees affected by citrus blight and declinio. Plant Disease, Saint Paul, v.72, n.12, p.1058-1060, 1988.

BERGER, R. A causa e o controle do declínio dos citros. Laranja, Cordeirópolis, v.19, n.1, p. 91-105, 1998.

BOMAN, B.J.; BERGER, R.D.; DERRICK, K.S.; BATTIKHI, A.M. Citrus blight incidence under diferent fertilization and liming programs in Florida Flatwoods. Proceedings of the Florida State Horticultural Society, Tallahassee, v.118, p. 35-39, 2005.

CARLOS, E.F.; LEMOS.; E.G.M.; DONADIO, L.C. O declínio dos citros. Laranja, Cordeirópolis, v.21, n.1, p.175-203, 2000. 
CASTRO, P.R.C. Declínio: uma anomalia fisiológica dos citros. Laranja, Cordeirópolis, v.12, n.2, p.381400, 1991.

DERRICK, K.S. Evidências indicam que o declínio dos citros é uma doença infecciosa. Laranja, Cordeirópolis, v.19, n.1, p.107-116, 1998.

DERRICK, K.S.; BARTHE, G.A.; HEWITT, B.G.; IREY, M.S.; LEE, R.F.; ALBRIGO, L.G. Detection of citrus blight by serological assays. Proceedings of the Florida State Horticultural Society, Tallahassee, v.105, p.26-28, 1992.

LARANJEIRA, F.F.; AMORIN, L.; BERGAMIN FILHO, A.; AGUILAR-VILDOSO, C.I.; COLETA FILHO, H.D. Fungos, procariontes e doenças abióticas. In: MATTOS JUNIOR, D.; DE NEGRI, J.D.; PIO, R.M.; POMPEU JUNIOR, J. Citros. Campinas: Instituto Agronômico e Fundag, 2005. p.510-566.

LEE, R.F.; MARAIS, L. J.; TIMMER, L.W.; GRAHAM, J.H. Syringe injection of water into the trunk: a rapid diagnostic test for citrus blight. Plant Disease, Saint Paul, v.68, n.6, p.511-513, 1984.

LIMA, J.E.O.; BORDUCCHI, A.S. Observations on citrus blight in Sao Paulo, Brazil. Proceedings of the Florida State Horticultural Society, Tallahassee, v.95, p.72-75, 1982.

MARAIS, L.J. Characteristics of citrus blight in South Africa. In: INTERNACIONAL SYMPOSIUM OF CITRUS CANKER, DECLÍNIO/BLIGHT AND SIMILAR DISEASES, 1., 1987, São Paulo. Proceedings..., Campinas: Fundação Cargill, 1988. p. 285-292.

MIYAZAWA, M.; PAVAN, M. A.; MURAOKA, T.; CARMO, C.A F.de S. do; MELLO, W. J. de. Análise química de tecido vegetal. In: SILVA, F.C. da. (Org.). Manual de análises químicas de solos, plantas e fertilizantes. Brasília: Embrapa Comunicação para Transferência de tecnologia, 1999. p.171-223.

POMPEU JUNIOR, J. Porta-enxertos. In: MATTOS JUNIOR, D.; DE NEGRI, J.D.; PIO, R.M.; POMPEU JUNIOR, J. Citros. Campinas: Instituto Agronômico e Fundag, 2005. p.61-104.
RODRIGUES, O.; ROSSETTI, V.; MÜLLER, G.W. Declínio de plantas cítricas em São Paulo. In: CONGRESSO BRASILEIRO DE FRUTICULTURA, 5. 1979, Pelotas. Anais... Pelotas: Sociedade Brasileira de Fruticultura, 1979. p.927-932.

ROSSETTI, V.; BERETTA, J.G.; TEIXEIRA, A.R.R. Experimental transmission of declinio by approach-root-grafting in São Paulo State, Brazil. In: INTERNATIONAL ORGANIZATION OF CITRUS VIROLOGISTS CONFERENCE, 11., 1989, Orlando. Proceedings... Riverside: University of California, 1991. p.250-255.

SWINGLE W.T.; WEBBER H.J. The principal diseases of citrus fruits in Florida. Florida; USDA, 1896. p.50. (Bulletin, 8)

TIMMER, L.W. "Blight"- Uma doença infecciosa dos citros. In: SEMINÁRIO INTERNACIONAL SOBRE PORTA-ENXERTOS DE CITROS, 1., 1990, Bebedouro. Anais... p.195-209.

TUCKER, D.P.H.; LEE, R.F.; TIMMER, L.W.; ALBRIGO, L.G.; BRLANSKY, R.H. Experimental transmission of citrus-blight. Plant Disease, Saint Paul, v.68, p.979-980, 1984.

WUTSCHER, H.K. Seasonal changes in zinc and water-soluble phenolics in the outer trunk wood of healthy and blight-affected sweet orange trees. Hortscience, Alexandria, v.16, n.2, p.157-158, 1981.

WUTSCHER, H.K.; COHEN, M.; YOUNG, R.H. Zinc and water-soluble phenolic levels in the wood for the diagnosis of citrus blight. Plant Disease Reporter, Beltsville, v.61, n.7, p.572-576, 1977.

YOUNG, R.H.; ALBRIGO, L.G.; COHEN, M.; CASTLE, W.S. Rates of blight incidence in trees on Carrizo citrange and other rootstocks. Proceedings of the Florida State Horticultural Society, Tallahassee, v.95, p.76-78, 1982. 